\title{
The creation of effective states in the OECD since 1870 : The role of inequality
}

\section{Madsen, Jakob B}

2017

Madsen , J B , Wang , C \& Steiner , B E 2017 , ' The creation of effective states in the OECD since 1870 : The role of inequality ' , European Journal of Political Economy, vol. 50 , pp. 106-121 . https://doi.org/10.1016/j.ejpoleco.2017.03.007

http://hdl.handle.net/10138/300210

https://doi.org/10.1016/j.ejpoleco.2017.03.007

cc_by_nc_nd

acceptedVersion

Downloaded from Helda, University of Helsinki institutional repository.

This is an electronic reprint of the original article.

This reprint may differ from the original in pagination and typographic detail.

Please cite the original version. 


\title{
Industry Diversity, Competition and Firm-Relatedness: The Impact on Employment Before and After the 2008 Crisis
}

\author{
Forthcoming in: Regional Studies
}

\section{CONG WANG + +* $^{*}$ JAKOB B. MADSEN§ and BODO STEINERTI}

$\dagger$ Department of Business and Economics, University of Southern Demark, 2 Alsion, 6400 S $\phi n d e r b o r g$, Denmark. Email: cong@sam.sdu.dk

† Bond Business School, Bond University, Qld 4226, Australia. Email: cowang@bond.edu.au

$\S$ Department of Economics, Monash University, Victoria 3800, Australia. Email: jakob.madsen@monash.edu

Il Department of Entrepreneurship and Relationship Management, University of Southern Denmark, 2 Alsion, 6400 Sønderborg, Denmark. Email: $\underline{\text { bsteiner@sam.sdu.dk }}$

\| Department of Resource Economics and Environmental Sociology, University of Alberta, Edmonton, Canada, bsteiner@ualberta.ca

*Corresponding Author 


\title{
Industry diversity, competition and firm-relatedness: The impact on employment before and after the 2008 crisis
}

\begin{abstract}
This study investigates the extent to which indicators of external scale economies impacted employment growth in Canada over the period 2004-2011. We focus on knowledge spillovers between firms while accounting for Marshallian specialization, Jacobs' diversity, and competition by industry, as well as related and unrelated firm varieties in terms of employment and sales. We find that the employment growth effects of local competition and diversity are positive, while the effect of Marshallian specialization is negative.

Diversification is found to be particularly important for employment growth during the Global Financial Crisis and immediately thereafter.
\end{abstract}

Keywords. External scale economies, Employment growth, Entropy of variety, Firms, Canada JEL classifications: C21, G01, R11

\section{INTRODUCTION}

The seminal paper of Glaeser, Kallal, Scheinkman and Shleifer (1992) sparked ongoing interest in the effects of knowledge spillovers between firms and, particularly, the extent to which knowledge spillovers, and consequently growth, are influenced by industrial concentration, competition and diversity.

In this paper a unique Canadian dataset is used to test the extent to which industrial concentration, competition and diversity, among other factors, influence firms' employment growth performance. The paper makes four contributions to the literature. First, and in contrast to the only existing published Canadian study by Shearmur and Polese (2005), this paper assesses more recent periods in greater spatial detail in order to identify whether the Global Financial Crisis (GFC) has had a moderating impact on the relationship between external scale economies and employment growth. Relative to the approach used here, Shearmur and Polese (2005) focus on the period 19712001, and analyze several aggregate geographic units (382 areas) with 18 industries classified by SIC 2. Furthermore, the analysis in this paper is the first study for Canada to uncover drivers of 
employment growth, focusing on competition, specialization, diversity, and firm-related and unrelated variety. As argued below there are several benefits from considering Canada.

Second, in light of the firm-level nature of the dataset itself, this paper contributes to the under-researched area of the impact of firm-relatedness on growth at the individual firm level. The studies of Bishop and Gripaios (2010) on Britain and van Oort, Geus and Dogaru (2014) on panEuropean regions are the closest published examples of the impact of firm-relatedness on growth so far. Frenken, van Oort and Verburg (2007), Forni and Paba (2001) and Feldman and Audretsch (1999) also examine the impact of firm-relatedness on growth, however, they focus on country or aggregate provincial level data. Furthermore, although both Bishop and Gripaios (2010) and van Oort et al. (2014) also use entropy measures to examine related and unrelated varieties based on employment at the 2-digit and 4-digit industry levels, the present paper explores relatedness in terms of both employment and sales at the individual firm level.

Third, the paper extends the analysis of Glaeser et al. (1992) and van Soest, Gerking, and van Oort (2006) by accounting for related and unrelated firm varieties as measured by two entropy measures based on firm employment and sales. The related variety represents variety in terms of different industries and is measured by an industry's employment and sales share at a certain specific classification level (in our case, the individual firm level), which belongs to a common higher-up (less specific) classification level (in our case, the 6-digit SIC). Unrelated varieties, as compared with varieties at the individual firm level, represent varieties at the 6-digit SIC level. These two measures are constructed for each observation (i.e. CSD-4-digit industry) in our sample. The inclusion of entropy measures is deemed an important complement to the existing concept of diversity in the spatial context (van Oort et al., 2014).

Finally, and most importantly, covering the pre- and the post-GFC periods, the regression results give insight into the industrial structure that is best suited to dealing with economic crises and, therefore, how the industrial structure influences the employment effects of adverse shocks. In particular, we investigate whether the effects of related and unrelated diversity change during 
downturns by comparing the employment growth effects of diversity before and after the GFC. These results will cast light on the so-called "portfolio theory" (see e.g. Attaran, 1986; Haug, 2004) in which diversity protects a region from sector-specific external demand shocks. A sufficient number of different sectors in diversified regions can, at least to a certain extent, offer job opportunities for dismissed employees from declining sectors. Hence, a diversified sector structure may be analogous to an entrepreneurial investment strategy, where risk is spread over various investment activities.

There are three reasons why the Canadian data give additional insight into the effects of industrial structure on firm performance. First, the Canadian dataset, which covers all the companies in Canada, gives a rare opportunity to examine this matter in the context of a large North American country with several territories. Second, Canada is quite different from many European countries by being a resource-rich and less densely populated advanced country. The Canadian results can be representative and provide implications for similar resource-rich and sparsely populated advanced countries such as Australia, New Zealand, the United States, and Scandinavian countries. Third, since Canada has a highly diversified industrial structure across almost all major SIC/NAIC categories, the results are likely to effectively reveal the effects of concentration, competition and diversity on employment growth.

\section{LITERATURE}

In current literature, there are two broad hypotheses on the nature of external economies of scale. Under the 'Industrial district-argument' put forward by Marshall (1890), the spatial concentration of production may sustain asset-sharing, the provision of specific goods and services by specialized suppliers, and a local labor market pool. A local concentration of production is therefore expected to reduce production costs incurred by individual firms in the industrial district or cluster, as well as generate economies of scale external to the firm. As put forward by Marshall (1890), Arrow (1962), and Romer (1986), and later formalized by Glaeser et al. (1992) as the Marshall-Arrow-Romer 
(MAR) model, the specialization hypothesis argues that knowledge tends to be industry-specific. Consequently, spillovers are expected to arise between firms within the same industry and can only be supported by regional concentrations of similar industries. These intra-industry spillovers are known as localization or 'specialization' externalities.

Jacobs (1969), by contrast, suggests that knowledge spillover can also arise between complementary as well as similar industries. Jacobs (1969) argues that the exchange of complementary knowledge across diverse firms and economic agents facilitates search and experimentation in innovation. A diversified regional production structure is therefore expected to increase the stock of knowledge available to the individual firm, and to give rise to urbanization or 'diversification' externalities. ${ }^{1}$

Porter (1990), like MAR, supports the hypothesis that knowledge spillovers in specialized geographically-concentrated industries stimulate growth. He stresses, however, that local competition, as opposed to local monopoly, fosters the pursuit and rapid adoption of innovation. Porter's externalities are maximized in cities with geographically specialized, competitive industries.

Since the seminal article by Glaeser et al. (1992), the empirical literature investigating the impact of MAR- and Jacobs- externalities has expanded rapidly (see e.g. Johansson, Karlsson and Stough, 2001; Rosenthal and Strange, 2003a; Stuart and Sorenson, 2003 and Van Oort and Stam, 2006). Following the Glaeser et al. (1992) approach, Shefer and Frenkel (1998) as well as Paci and Usai (1999) find evidence that both specialization and diversification externalities positively affect regional innovativeness in Israel and Italy. In contrast, Feldman and Audretsch (1999) argue that diversification rather than specialization externalities promote regional innovative activity in the United States. $^{2}$

\section{EMPIRICAL ANALYSIS}




\section{Data and Descriptive Statistics}

Annual Canadian business location data is employed from Environics Analytics, which contains all registered Canadian firms (more than 1.5 million) from 2004 to 2011. Similar to van Soest et al. (2006) and following Glaeser et al. (1992), cross-section analyses are carried out for the six largest industries for a given regional identifier, aggregating our firm level data onto the Census subdivision (CSD)-industry level (for a robustness check, we also use census subdivision (CD) where the six largest industries within each of the 2,509 CSDs are chosen from 2004-2011 (2,544 CSDs for the period 2008-2011). This gives a total of 15,054 CSD-industries under observation. ${ }^{3}$ For the regressions covering the period 2004-2011, all explanatory variables are measured in 2004 (the beginning year) and matched to available CSDs in the 2011 data to calculate growth from 2004 to 2011. The explanatory variables in the pre-GFC (2004-2008) and the post-GFC (2008-2011) regressions are measured in 2004 and 2008. We refrain from taking period averages of the explanatory variables because it would result in a complex serial correlation pattern and compromise the consistency of the parameter estimates. In addition, a change in the dissemination area code definition from Statistics Canada from 2001 to 2006 had to be addressed so that the 2004 codes could be transformed to the 2011 codes. In order to calculate the inverse distance-weighted version of competition, concentration and industry diversity, all of the above had to be matched to the CSDs in the distance data, giving a total of 2,509 CSDs. For these CSD industries, we examine the effect of external scale economies (specialization, diversity, competition) on local firm employment growth.

Like Glaeser et al. (1992) and van Soest et al. (2006), we are unable to include tangible and intangible capital as an input in the firm production function as these data are not available in the dataset. The omission of fixed capital means that we are unable to capture labor-saving technological progress or innovations that result in further accumulation of capital. The omission of intangibles such as patents, copyrights, trademarks, franchises and the value of investment in R\&D that has not resulted in patents and copyrights from the regressions implies that we cannot account 
for the employment effects of firms and industries that invest in R\&D. Since intangible capital is probably complementary to labor, the growth in employment is likely to be underestimated for high-tech firms and industries, resulting in biased coefficient estimates to the extent that intangible capital is correlated with the included regressors. Future work would clearly benefit from inclusion of tangible and intangible capital stock in the regressions.

Table 1 provides summary statistics and definitions of the main variables. ${ }^{4}$ The dependent variable, employment growth, is measured by the change in the log of employment in a census subdivision-industry over the period 2004-2011 $\left(\log \left(\frac{e m p_{2011}}{e m p_{2004}}\right)\right.$ in Table 1). The Marshallian external scale effect (concentation) is measured by the location quotient, defined as the proportion of local employment accounted for by a 4-digit industry in a specific census subdivision divided by the proportion of employment accounted for by the industry nationally (see Table 1). Local competition (competition) is measured as the ratio of establishments per worker in a CSD-industry to establishments per worker in that industry at the national level (see Table 1). The competition measure is region specific as stressed by Leach (1992), Barrios, Bertinelli and Strobl (2006) and Drucker (2011), in that it reflects the ratio of the local to the national average of establishments per worker; however, we do acknowledge that the national average in the denominator may degrade the level of heterogeneity across regions.

Industrial diversity (diversity ind $_{\text {) }}$ in a CSD-industry is measured as the percentage of employment in the five other largest industries (out of the six largest industries selected for each CSD), excluding the one under observation, as shown in Table 1. Similar values of general diversity across all six largest industries in a particular CSD indicate a high diversity. Big differences in the values across the six largest industries in a particular CSD indicate the existence of dominant industries, and hence, low diversity. While being standard in the literature (see, e.g. Glaeser et al. 1992), the downside of this measure of industry diversity is that it does not take into account firm relatedness and is influenced by data considerations. Related and unrelated firm varieties are 
measured by two entropy measures based on firm employment and sales (see variable definitions for $E_{U V e m p}, E_{U V s a l e}, E_{R V e m p}$ and $E_{R V s a l e}$ in Table 1).

Related varieties represent varieties at a certain level of classification (in our case, the individual firm level), which belong to a common higher-up (less specific) classification level (in our case, the 6-digit SIC). Unrelated varieties as compared with the varieties at the individual firm level, are the varieties at the 6-digit level. These two measures are constructed for each observation in our sample, (i.e. the CSD-4-digit industry). In addition, the regressions also include the inverse geographic distance-weighted average versions of concentration (concentration ${ }_{w}$ ), competition $\left(\right.$ competition $\left._{w}\right)$ and industry diversity $\left(\right.$ diveristy $\left._{\text {indw }}\right)$ to control for spillovers of external scale economies to the CSD under observation from all other CSDs. Other control variables include total employment in the CSD-industry in $2004\left(e m p_{2004}\right)$ and its distance-weighted counterpart $\left(e m p_{2004 w}\right)$, total employment in the CSD outside the industry under consideration in 2004 $\left(e m p_{2004 o t h e r}\right)$ and its distance-weighted counterpart (emp 2004 otherw $)$. These four variables are included to capture the scale of activity in a CSD-industry. Following the literature, the standard industry classification codes (SIC and NAIC) is used to measure concentration, competition and diversity. A tailored made industry classifications to construct these measures would have been more ideal; however, this is outside the scope of this paper.

[Table 1 here]

\section{Estimation method}

To explore the potential impact of external scale economies on employment growth, the effect of external scale economies on employment growth in Canada is estimated for the periods 2004-2011 and 2008-2011. First conventional OLS regressions are run and we check for spatial autocorrelation. To address the potential problem of spatial autocorrelation, which causes biased 
estimates from OLS, the Cliff-Ord model (Cliff and Ord, 1981) is estimated by both maximum likelihood (ML) and generalized spatial two-stage least squares (GS2SLS). The GS2SLS technique is utilized because there is still no large-sample theory for the distribution of the ML for the CliffOrd model (see Drukker, Peng, Prucha and Raciborski, 2012). Furthermore, Arraiz, Drukker, Kelejian and Prucha (2010) show that the GS2SLS estimator produces consistent estimates when the disturbance terms are heteroskedastic, while the ML estimator produces inconsistent estimates. Finally, the GS2SLS estimator creates instruments within the data using instrumental variables derived from the spatial weighted version of the original explanatory variables and the GMM method (Drukker et al. 2012). Specifically, for the OLS model during the period 2004-2011, the following equation is estimated:

$$
\begin{aligned}
& \log \left(\frac{\text { emp }_{2011}}{\text { emp }_{2004}}\right)=\alpha_{0}+\alpha_{1} \text { concentration }+\alpha_{2} \text { competition }+\alpha_{3} \text { diversity }_{\text {ind }}+ \\
& \alpha_{4} E_{U V e m p}+\alpha_{5} E_{U V \text { sale }}+\alpha_{6} E_{R V \text { emp }}+\alpha_{7} E_{R V \text { sale }}+\alpha_{8} \text { emp }_{2004}+\alpha_{9} \text { emp }_{2004 \text { other }}+ \\
& \alpha_{10} \text { emp }_{2004 w}+\alpha_{11} \text { emp }_{2004 o t h e r w}+\alpha_{12} \text { concentration }_{w}+\alpha_{13} \text { competition }_{w}+ \\
& \alpha_{14} \text { diversity }_{\text {indw }}+\beta \text { ind }_{\text {dum }}+\gamma \operatorname{CSD}_{\mathrm{dum}}+\varepsilon
\end{aligned}
$$

where $\varepsilon$ is the $i$ id error term, $i n d_{d u m}$ is a vector of industry dummies, and $C S D_{d u m}$ is a vector of CSD dummies.

For the Cliff-Ord model equations (2) and (3) are estimated simultaneously:

$$
\begin{aligned}
& \log \left(\frac{\text { emp }_{2011}}{\text { emp }_{2004}}\right)=\beta_{0}+\lambda W \log \left(\frac{e m p_{2011}}{\text { emp }_{2004}}\right)+\beta_{1} \text { concentration }+\beta_{2} \text { competition }+ \\
& \beta_{3} \text { diversity }_{\text {ind }}+\beta_{4} E_{U V e m p}+\beta_{5} E_{U V s a l e}+\beta_{6} E_{R V e m p}+\beta_{7} E_{R V \text { sale }}+\beta_{8} \text { emp }_{2004}+ \\
& \beta_{9} \text { emp }_{2004 o t h e r}+\beta_{10} \text { emp }_{2004 w}+\beta_{11} \text { emp }_{2004 o t h e r w}+\beta_{12} \text { concentration }_{w}+ \\
& \\
& \beta_{13} \text { competition }_{w}+\beta_{14} \text { diversity }_{\text {indw }}+\text { uind } \text { dum }_{\text {dum }}+\gamma \delta+u \\
& u=\rho M u+\epsilon
\end{aligned}
$$

where $\lambda$ denotes the coefficient of the spatial lag term, $W \log \left(\frac{e m p_{2011}}{e m p_{2004}}\right)$, with $W$ being the spatial weighting matrix for the dependent variable, $\rho$ is the coefficient of the spatial error term $M u$, with $M$ 
being the spatial weighting matrix for the error term, $u$ is the spatially autocorrelated error term, and $\epsilon$ is the iid error term. The significance of $\lambda$ and $\rho$ indicate the goodness of fit of the spatial model. The above models are estimated for a cross-section sample without time dimensions.

\section{Key regression results}

Table 2 presents regression results for the period 2004-2011 for different combinations of the control variables using the OLS, ML and GS2SLS estimators (the variables are defined in Table 1). We report standardized coefficients for the seven key variables in square brackets below the nonstandardized coefficients. The low $p$-values of Moran's I tests indicate the presence of spatial autocorrelation. The significant $\rho$ and $\lambda$ in the ML and GS2SLS regressions, furthermore, justify the use of the Cliff-Ord general spatial model. The positive signs on $\lambda$ and $\rho$ suggest that both the dependent variable (employment growth) and the error term under observation in a specific CSD and industry are positively influenced by spatial spillovers from other CSDs.

Consider first the regressions in the $1^{\text {st }}$ columns in which all control variables are included. The coefficients of concentration (Marshallian specialization) are all significantly negative, suggesting that firms tend to grow at slower rates when they are locally concentrated; a result that is consistent with the findings of Rosenthal and Strange (2003b) and Drucker $(2011,2015)$. In almost all cases the coefficients of local competition and cross-industry diversity are significantly positive. However, the magnitude (absolute value) of the impact of cross-industry diversity is large compared with effects from local competition as evidenced by the standardized coefficients of these two variables. These results support Jacobs' (1969) view that diversity promotes regional employment growth and urbanization, rather than the Marshallian 1890 view of specialization. The findings on specialization and general diversity in this paper are consistent with the findings from Glaeser et al. (1992) and van Soest et al. (2006). 


\section{Firm relatedness and unrelatedness}

Firm relatedness and un-relatedness (entropy measures based on sales and employment shares) are mostly insignificant in the OLS and GS2SLS regressions, but highly significant in the ML regressions, suggesting inconclusive results. However, taking a closer look at the results for which the entropy measures are significant, firm relatedness and un-relatedness characterized by employment have the exact opposite effects on employment growth, compared to firm relatedness and un-relatedness characterized by sales. Thus, a mix of firms with heterogeneous (unrelated) employment characteristics and a mix of firms with homogenous (related) sales figures tends to promote employment growth.

There are three potential explanations for this phenomenon. First, as argued by Attaran (1986) and Haug (2004), unrelated variety is essentially a portfolio strategy to protect a region from external demand shocks. A homogenous group of firms in terms of regional employment shares can be viewed as having correlated labor markets and networks, producing similar types of goods. ${ }^{5}$ This, in turn, will elevate the risk of a serious employment growth slowdown as a result of an adverse demand shock. For example, in a given region where both shoe and toy manufacturing companies are co-located and agglomerated (belonging to different industries), both firm types may be similar in terms of relying on mainly labor for production, reflected in the level of relatedness based on employment. In the case of an external shock to their demand, both may be severely affected, and risk jointly going out of business. The above rationale of relatedness based on employment may help to explain why we find the employment entropy that measures unrelated firm variety is highly significant for the period 2008-2011, as further discussed below.

Second, the opposite effects of the entropy measures based on sales suggest that related sales shares, which promote employment growth, may be supportive of the 'anchor tenant hypothesis' (Feldman 2003). A region may benefit from the presence of large firms (measured by revenue) since the anchor firm provides a minimum sales basis for other firms in the region, thereby creating positive spillovers. The anchor tenant hypothesis may also help explain the positive signs 
on the coefficients of competition, since the presence of a large anchor tenant firm may raise the product standard in a particular market in which many similar firms compete against each other. This will foster competition and create a positive spillover for other smaller firms' employment growth. The findings in this paper for the related variety based on sales are consistent with the findings of Frenken et al. (2007) and van Oort et al. (2014), whereas the findings for unrelated variety based on employment are not, however, they are still consistent with the finding Bishop and Gripaios (2010).

Third, the finding that firm relatedness and un-relatedness by employment have opposite effects on employment growth compared to firm relatedness and un-relatedness characterized by sales may be an outcome of multicollinearity between these variables. ${ }^{6}$ To check for this possibility the variables representing relatedness and un-relatedness by employment ( $E_{U V e m p}$ and $\left.E_{R V e m p}\right)$ are excluded from the regression in column 4 in Appendix Table A2 in which the ML estimator is used. The coefficient of $E_{U V s a l e}$ remains negative and highly significant and the coefficient of $E_{R V s a l e}$ remains positive and significant. If, conversely, the variables representing relatedness and unrelatedness by sales ( $E_{U V \text { sale }}$ and $E_{R V \text { sale }}$ ) are excluded from the regression, (column 3 in Appendix Table A2), the coefficient of $E_{R V e m p}$ remains negative and significant, however, the coefficient of $E_{\text {UVemp }}$ loses its statistical significance. The results remain almost unaltered if the variables representing relatedness and un-relatedness are entered individually (columns 5 to 8 in Table A2) and the coefficient of $E_{U V e m p}$ regains its statistical significance and remains negative. From these results it can be concluded that the results are not significantly affected by multicollinearity and that the baseline regression results remain intact.

The results further indicate that cross-location spillover effects (inverse distance weighted version of the variables) are present for diversity and competition, as well as employment levels in 2004 for the industry under consideration and outside of the industry under consideration, but not present for specialization. In Table 2, the coefficients of concentration ${ }_{w}$ are not significant,

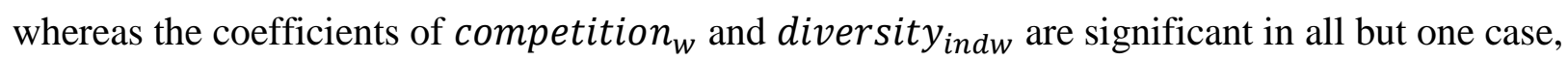


thus providing further support for the importance of diversity and competition for local employment growth.

Moreover, the positive effects of diversity and competition tend to spread over geographic distance, while the negative effects of specialization tend to be confined locally, and have no further impact on other neighboring regions, eventually dying out quickly with distance. This is not fully in tune with the findings of van Soest et al. (2006) for the Netherlands, where no cross-location spillover effect is found, either for diversity/competition or for concentration, except for manufacturing.

When the variables representing relatedness and un-relatedness are excluded from the regressions, there are no significant differences in the magnitudes of the coefficients of concentration, diversity and competition (see Table 2, the (1)-columns estimated by all three methods, OLS, ML and GS2SLS, or the employment-related variables (2)-columns estimated by all three methods, there are no significant differences in the magnitudes of the coefficients of concentration, diversity and competition). Finally, to check whether the results are predominantly driven by the between variation of the data, the industry and regional fixed effects dummies are removed from the ML and GS2SLS regressions in the first two columns in Table A2. The parameter estimates are quite similar to those of the baseline regressions, which implies that the identifying variation in the data is mostly coming from the within variation in the data and that there is identifying consistency in the between, as well as the within, variation in the data.

[Table 2 here]

\section{Distinguishing upturns and downturns}

Table 3 displays the regression results from the pre-GFC (2004-2008) and the post-GFC (20082011). Only the ML and the GS2SLS regressions are presented to preserve space. The coefficients 
of concentration and diversity are both highly positively significant in the two periods and their coefficients are quite similar. The coefficient estimates $\alpha_{8}-\alpha_{14}$ are also mostly consistent across the two sample periods. However, there are two noticeable changes in going from the pre- to the post-GFC period.

First, the coefficient of concentration becomes statistically and economically much less significant in terms of being detrimental to employment growth during the downturn compared to the pre-crisis period. This is likely caused by a countervailing effect of specialization during the financial crisis. Regional clusters (i.e. regions with high specialization) could potentially have suffered more from demand shocks than diversified areas during the GFC, causing the financial crisis to worsen. However, regional clusters can have the characteristics of an intact industrial base with fully internalized supply chains, which may be less sensitive to economic shocks due to the tangible and intangible assets accumulated over the years (Maskell and Malmberg, 1999). This path-dependent and interactive character of knowledge creation (Maskell and Malmberg, 1999) makes these regional clusters more likely to maintain a certain level of operation during downturns compared with other regions. Overall, the effects of specialization on regional employment growth during the GFC is ambiguous.

The second noticeable change in moving from the period 2004-2008 to the period 20082011 is the change in the impact of firm relatedness on employment growth. Diversities based on firm relatedness and un-relatedness become much more important during the 2008-2011 downturn compared to the pre-GFC period. Specifically, the significance of the coefficients of diversity ind do not die out during the period 2008-2011. ${ }^{7}$

These findings support the portfolio argument of Attaran (1986) and Haug (2004) that diversification in employment and sales alleviates adverse employment growth effects of negative demand shocks, since regions with related diversified firms in terms of employment still face the same kind of labor demand shocks during the crisis years. Relatedness and un-relatedness effects are, in terms of statistical significance, much more important in the period 2008-2011 than in the 
period 2004-2008. Furthermore, the size of coefficients also increases for both related and unrelated variety, which further strengthens the importance of diversity, in terms of related and unrelated variety, during the crisis period. In summary, our estimation results suggest that (i) cross-location externalities for general diversity are weaker during the period 2008-2011 than the pre-GFC period; and (ii) particular types of diversity (general and entropy in terms of employment and sales) can have an important differential impact on employment growth in the case of an adverse shock to the economy, such as the GFC.

The evidence in favor of the portfolio argument implies that economies with a large diverse portfolio of firms are less susceptible to adverse demand shocks because their industries have different cyclical properties - i.e. countercyclical industries partly or entirely neutralize the adverse employment effects of demand shocks in the pro-cyclical industries. Our diversification results are consistent with the diversity argument of Jacobs (1969) and the findings of Bishop and Gripaios (2010) for the UK and Frenken et al. (2007) for the Netherlands. Thus, it can be concluded that economic diversity may be an appropriate target for regional policy makers.

\section{Robustness checks and sector analysis}

A battery of robustness tests are discussed and presented in Appendix A2. We test for alternative sampling of industries (with four and eight industries per CDS instead of 6), alternative geographic composition of industries, inclusion and exclusion of fixed effects, multicollinearity, non-linear relationships between agglomeration/diversity forces and regional employment growth. The baseline regression results are robust to these considerations; thus giving further credibility to the baseline regression results.

Finally, we decompose the sample into agriculture, industry and services in Appendix A3 as it is conceivable that the industrial structure and spillover-effects are different across main sectors. The significance and sign of coefficients for the focus variables are mostly consistent with those of 
the baseline regressions; however, there is some variation across sectors, which may be an outcome of a small-sample bias.

[Table 3 here]

\section{CONCLUSIONS}

This paper provides novel and detailed evidence that external scale economies contribute to employment growth in the case of Canada. For the entire period under investigation, 2004-2011, the results show that concentration (Marshallian specialization) has a significantly negative impact on employment growth, whereas the effects of local competition and cross-industry diversity are significantly positive. Allowing for non-linear effects, employment growth is found to be steeply increasing in diversity and the interaction between diversity and competition. Furthermore, regardless of estimation period, the coefficients of diversity remain consistently highly positively significant to sectoral decomposition into industry and services (unsurprisingly, they is insignificant for agriculture), and industrial classification. Although the coefficients of concentration are significantly negative in the baseline regressions, these results are not robust to estimation period (insignificant in the pre-2008 period), sectoral decomposition (insignificant for the industry sector), and inclusion of squared terms (existence of a certain threshold level of competition, beyond which the current positive growth effects of competition will decelerate and eventually turn negative). Finally, the coefficients of competition are consistently highly positively significant and robust determinants of employment growth. Overall, our results support the view of Jacobs (1969) that diversity promotes regional growth, rather than the Marshallian (1890) view of specialization and, as found in most other studies, that employment is strongly positively related to competition.

Special attention is given to the nexus between industrial structure and employment growth during the pre-GFC (2004-2008) and post-GFC (2008-2011) periods. For the post-GFC period 
(2008-2011), the evidence points towards diversities based on firm relatedness and un-relatedness becoming more significant compared with the pre-crisis period, 2004-2008. Furthermore, the coefficients of both related and unrelated variety increase during the period 2008-2011; thus further strengthening the importance of diversity in mitigating employment shocks.

Acknowledgements - The authors are grateful to participants at the 2013 research seminar series at the Institute for Regional Research (IfR), University of Kiel, and the 2014 Uddevalla Symposium for helpful suggestions and comments. They also thank Hendrik Lüth, IfR, for outstanding research assistance.

Disclosure statement - No potential conflict of interest was reported by the authors.

Funding - Bodo Steiner gratefully acknowledges research support from the IfR during his sabbatical there, during which part of this research was conducted. Jakob B. Madsen acknowledges financial support from the Velux Fund Visiting Professor Program that enabled him to undertake the research while visiting the University of Southern Denmark.

\section{NOTES}

${ }^{1}$ Dixit and Stiglitz (1977) further contend that diversity and variety in consumer goods or in producer inputs can yield external scale economies as consumers' welfare depends on the variety of goods they can obtain in a specific region. Duranton and Puga (2003) provide a comprehensive review of the two strands of literature and propose the key micro-foundations of external scale economies: sharing, matching and learning, corresponding to the three elements of Marshall's 'industrial district-argument': labor market pooling, specialized suppliers and knowledge spillovers.

${ }^{2}$ A detailed literature review is provided in Appendix A1.

${ }^{3}$ Each observation is a particular CSD-industry, where not every CSD has the exact same industries. The six largest firms (measured by employment) within each of the 2,509 CSDs are selected, giving a total of $2,509 \times 6=15,054$ observations (CSD-industries). The frequency distribution of industries among the 2,509 CSDs can be found in Figure A1 in the appendix. From Figure A1, it is evident that both concentration and diversity of Canadian industries are present in our data, with very few industries concentrated in less than 10 CSDs and only few industries are omnipresent in over 2,000 CSDs. Moreover, our results are not sensitive to whether we use the SIC or the NAIC industry classification (see results in the last two columns of Appendix Table A2). To explore spatial spillovers across regions, as many regions as possible are included in the study, and hence the first choice of regions is CSD, albeit the CD (Census division) classification is also used in the robustness checks in Appendix Table A1. The number of industries in each 
CSD ranges from 3 to 12. If too many industries, say 9, were considered for each CSD, we would effectively exclude many observations, as CSDs with less than 9 industries would not be considered. Hence, following Glaeser et al. (1992) and van Soest et al. (2006), the 6 largest industries in each CSD are selected for the core regressions. To ensure the results are not driven by the numbers of industries in the index, 4 and 8 industries per CSD are included in Appendix Table A1. Note that 5 and 7 industries per CSD were also tried, but did not change the principal results (not reported here).

${ }^{4}$ The Grubbs outlier test (see Grubbs, 1969) was performed to detect the number of outliers for each of the 7 key explanatory variables. Out of the 15,054 observations in the core sample, 1,476 outliers exist for the concentration variable, 125 for competition, 25 for diversity ind $_{\text {, }}, 33$ for $E_{U V \text { Ump }}, 39$ for $E_{U V \text { sale }}, 0$ for $E_{R V e m p}$ and 0 for $E_{R V s a l e}$. Excluding these outliers from the sample did not significantly affect results in terms of sign, significance or the magnitude of the coefficients of all key explanatory variables (see the results in the third last column in appendix Table A2).

${ }^{5}$ Johanssen and Quigley (2004) forward the hypothesis that networks can play a role in facilitating exchange, both within and between regional agglomerations, leading to complementarities between agglomeration and networks.

${ }^{6}$ The correlation table in Appendix Table A3 suggests high correlations between the related and unrelated diversity measures $\left(U V_{e m p}, U V_{\text {sale }}, R V_{\text {emp }}, R V_{\text {sale }}\right)$. Furthermore, these variables have Variance Inflation Factors (VIF values) well in excess of 10 (Appendix Table A4), thus giving further support for the presence of multicollinearity.

${ }^{7}$ Note here that the four firm relatedness variables are much better indicators of diversity than the general

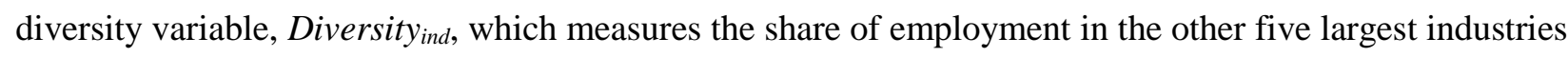
per CSD and, as such, doesn't capture the diversity in sales. Furthermore, Diversity ${ }_{i n d}$, does not distinguish between related and unrelated varieties. Therefore, the general diversity measure fails to capture the change in diversity during the period 2008-2011, because both related and unrelated variety based on employment become much more prominent during the crisis period.

\section{REFERENCES}

Arraiz, I., Drukker, D., Kelejian, H. H. and Prucha, I. R. (2010). A spatial Cliff-Ord-type model with heteroskedastic innovations: Small and large sample results. Journal of Regional Science, 50, 592-614. doi:10.1111/j.1467-9787.2009.00618.x

Arrow, K. J. (1962). The economic implications of learning by doing. Review of Economic Studies, 29, 155-172. doi:10.2307/2295952

Attaran, M. (1986). Industrial diversity and economic performance in U.S. Areas. Annals of Regional Science, 20, 44-54. doi:10.1007/BF01287240 
Barrios, S., Bertinelli, L. and Strobl, E. (2006). Geographic concentration and establishment scale: An extension using panel data. Journal of Regional Science, 46, 733-746. doi:10.1111/j.1467-9787.2006.00475.x

Bishop, P. and Gripaios, P. (2010). Spatial externalities, relatedness and sector employment in Great Britain. Regional Studies, 44, 443-454. doi:10.1080/00343400802508810

Cliff, A. D. and Ord, J. K. (1981). Spatial processes, models and applications. London: Pion.

Dixit, A. K. and Stiglitz, J. (1977). Monopolistic competition and optimum product diversity. American Economic Review, 67, 297-308. Retrieved from: http://www.jstor.org/stable/1831401

Drucker, J. (2011). Regional industrial concentration in the United States: Trends and implications. Economic Geography, 87, 421-452. doi: 10.1111/j.1944-8287.2011.01129.x

Drucker, J. (2015). An evaluation of competitive industrial structure and regional manufacturing employment change. Regional Studies, 49, 1481-1496. doi:10.1080/00343404.2013.837874

Drukker, D. M., Peng, H., Prucha, I. and Raciborski, R. (2012). SPPACK: Stata module for crosssection spatial-autoregressive models, Statistical software components. From http://EconPapers.repec.org/RePEc:boc:bocode:s457245

Duranton, G. and Puga, D. (2003). Micro-foundations of urban agglomeration economies (NBER Working Paper No. 9931). Cambridge. MA: National Bureau of Economic.

Feldman, M. (2003). The location dynamics of the US biotech industry: Knowledge externalities and the anchor hypothesis. Industry and Innovation, 10, 311-329. doi:10.1080/1366271032000141661

Feldman, M. and Audretsch, D. (1999). Innovation in cities: Science-based diversity, specialization and localized competition. European Economic Review, 43, 409-429. doi:10.1016/S00142921(98)00047-6

Forni, M. and Paba, S. (2001). Knowledge spillovers and the growth of local industries (Discussion Paper No. 2934). London: Centre for Economic Policy Research (CEPR).

Frenken K., Van Oort, F. G. and Verburg, T. (2007). Related variety, unrelated variety and regional economic growth. Regional Studies, 41, 685-697. doi:10.1080/00343400601120296

Glaeser E., Kallal H., Scheinkman J. and Shleifer A. (1992). Growth in cities. Journal of Political Economy, 100, 1126-1152. doi:10.1086/261856

Grubbs, F. (1969). Procedures for detecting outlying observations in samples. Technometrics , 11, 1-21. doi:10.1080/00401706.1969.10490657

Haug, P. (2004). Diversification, regional economies and employment development: An empirical analysis of selected German territories, Review of Regional Research, 24, 177-195. 
Jacobs, J. (1969). The economy of cities. New York: Vintage.

Johansson, B., Karlsson, C. and Stough, R. (2001). Theories of endogenous regional growth Lessons for regional policies. In, B. Johansson, C. Karlsson and R. Stough (eds.), Theories of endogenous regional growth, (pp. 406-414). Berlin: Springer-Verlag.

Johanssen, B. and Quigley, J. M. (2004). Agglomeration and networks in spatial economies. Papers in Regional Science, 83, 165-176. doi:10.1007/s10110-003-0181-z

Leach, D. F. (1992). Absolute vs. relative concentration in manufacturing industry, 1972-1985, South African Journal of Economics, 60(4), 386-399. doi:10.1111/j.18136982.1992.tb01046.x

Kelejian, H. H. and Prucha, L. R. (1999). A generalized moments estimator for the autoregressive parameter in a spatial model. International Economic Review, 40, 509-533. doi:10.1111/1468-2354.00027

Kelejian, H. H. and Prucha, L. R. (2004). Estimation of simultaneous systems of spatially interrelated cross sectional equations. Journal of Econometrics, 118, 27-50. doi:10.1016/S0304-4076(03)00133-7

Marshall A. (1890). Principles of economics (8th ed.). London: Macmillan.

Maskell, P. and Malmberg, A. (1999). Localised learning and industrial competitiveness. Cambridge Journal of Economics, 23(2): 167-185. doi:10.1093/cje/23.2.167

Paci, R. and Usai, S. (1999). Externalities, knowledge spillovers and the spatial distribution of innovation. GeoJournal, 49, 381-390. doi:10.1023/A:1007192313098

Porter, M.E. (1990). The Competitive Advantage of Nations. London: Macmillan.

Romer, P.M. (1986). Increasing returns and long-run growth. Journal of Political Economy, 94, 1002-1037. doi:10.1086/261420

Rosenthal, S. and Strange, W. C. (2003a). Evidence on the nature and sources of agglomeration economies. In J. V. Henderson and J.-F. Thisse (eds.), Handbook of urban and regional economics, (pp. 2119-2171). Amsterdam: North-Holland.

Rosenthal, S. and Strange, W. C. (2003b). Geography, industry organization, and agglomeration, Review of Economics and Statistics, 85(2), 377-393. doi:10.1162/003465303765299882

Shearmur R. and Polese M. (2005). Diversity and employment growth in Canada, 1971-2001: Can diversification policies succeed? Canadian Geographer, 49, 272-290. doi:10.1111/j.00083658.2005.00095.x

Shefer, D. and Frenkel, A. (1998). Local milieu and innovations: Some empirical results. The Annuals of Regional Science, 32(1), 185-200. doi:10.1007/s001680050069 
Stuart, T. and Sorenson, O. (2003). The geography of opportunity: spatial heterogeneity in founding rates and the performance of biotechnology firms. Research Policy, 32, 229-253. doi.10.1016/S0048-7333(02)00098-7.

Van Oort, F. G., Geus, S. and Dogaru, T. (2014). Related variety and regional economic growth in a cross-section of European urban regions. European Planning Studies, 23, 1110-1127. doi:10.1080/09654313.2014.

Van Oort, F. G. and Stam, E. (2006). Agglomeration economies and entrepreneurship in the ict industry (ERIM Report Series No. ERS-2006-016-ORG). Rotterdam: Erasmus Research Institute of Management.

Van Soest, D. P., Gerking, S. and van Oort, F. G. (2006). Spatial impacts of agglomeration externalities, Journal of Regional Science, 86, 5-30. doi:10.1111/j.1467-9787.2006.00488.x 